\title{
Survey on Automatic Number Plate Recognition System
}

\author{
Devesh Khaparde \\ Sinhgad Academy of Engineering, \\ Kondhwa, Pune
}

\author{
Heet Detroja \\ Sinhgad Academy of Engineering, \\ Kondhwa, Pune
}

\author{
Jainam Shah \\ Sinhgad Academy of Engineering, \\ Kondhwa, Pune
}

\author{
Rushikesh Dikey \\ Sinhgad Academy of Engineering \\ Kondhwa, Pune
}

\author{
Bhushan Thakare \\ Sinhgad Academy of Engineering \\ Kondhwa, Pune
}

\begin{abstract}
Number plate recognition is a system which is designed to capture the registered number plate of vehicles. It avails the user to identify and monitor running vehicles and extract their number plates and obtain their information from the RTO database .This survey paper focuses on the research done in automatic number plate recognition system from past several years and hence shows the advantages and disadvantages of the existing system. It shows the architecture and the methodology currently being used for the extraction of characters from number plate and displaying it. It has illustrated various methods to extract image frames from a streaming cctv footage, recognize the vehicle number and convert it into its corresponding text format. A Machine vision system for the car identification can also help a human operator and cultivate an objective to improve automation of the traffic controlling system using machine-learning tools.
\end{abstract}

\section{Keywords}

OCR (Optical Character Recognition), Automatic number plate recognition(ANPR).

\section{INTRODUCTION}

Over the recent period, various technologies consisting of innovative methods to extract vehicle number plate but it proves to be a difficult task. Vehicle proof of identity approach can be classified into four key steps such as license plate location extraction, pre-processing of image, character recognition in the licensed number plate and segmentation of characters. Every single step has its own significance in order to spot the vehicle, when license plate images are slanted and characters are not detectable or wrecked, which makes the segmentation of each character and recognition very monotonous [4].

Automatic number plate detecting system is an image processing technology used to recognize vehicles by their license number plates. This technology is gaining reputation in security and traffic installations for maintaining law enforcement on Civic roads, tool collection, administration of parking lots and stolen cars.

Vehicle licence plate number extraction plays an important part in various applications as follows automatic toll pay, traffic monitoring on highway, identification of stolen vehicles, parking lots access control etc. This kind of emerging protected innovative technology is now used in specific areas, such as military area, Supreme Court, parliament house [7].
In India, there are two forms of license plates, which are used:

1) Black characters with yellow background.

2) Black characters with white background [4].

Recognizing number plates in India is painstaking when equated to foreign license plate because number plates in India may have different fonts and shapes.

\section{SYSTEM ARCHITECTURE}

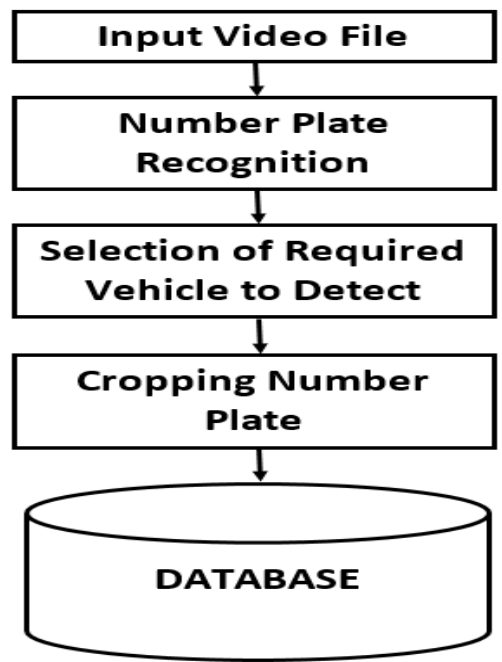

Fig 1 .System Architecture

In this system the video input is acquired from the LPR camera and then we locate the number plate in the video frame, which will find out the license plate of the vehicle automatically using lpr algorithm [11].

Select the vehicle from the video file derived and then locate and extract the number plate. In our proposed system we are extracting the necessary part of an image frame which we have collected from the camera video input file [11]. Cropping can be stated as follows,

$A=I(x 1, y 1, x 2, y 2)$

Where I is the input frame from which we will crop the necessary part to relate super resolution, while $\mathrm{x} 1, \mathrm{y} 1, \mathrm{x} 2$, and y2 shows the axis of the rectangle, and then show the image from the frame [11]. In the proposed system as we ponder on number plate detection, we extract the license plate, and store it in our database. 


\section{STUDIES AND FINDING}

\begin{tabular}{|c|c|c|c|}
\hline Author Name & Paper Title & Year & Description \\
\hline $\begin{array}{l}\text { 1. Worawut Yimyam } \\
\text { 2. Mahasak Ketcham }\end{array}$ & $\begin{array}{l}\text { The Automated Parking Fee } \\
\text { Calculation Using License } \\
\text { Plate Recognition System[2] }\end{array}$ & 2017 & $\begin{array}{l}\text { - Design automated parking fee calculation with license } \\
\text { plate recognition in order to reduce manual license plate } \\
\text { identification that is mostly employed at parking area of } \\
\text { other leading malls where the vehicle circulation is high } \\
\text { Advantage: It decrease manual operation including license } \\
\text { plate } \\
\text { identification and fee calculation, cut off the staff wage, } \\
\text { and save time for identifying plate and figuring out parking } \\
\text { fee as well. } \\
\text { Disadvantage: It requires the license plate images are } \\
\text { clear, sharp, no reflection and the background should be } \\
\text { white or light color and no pattern. }\end{array}$ \\
\hline $\begin{array}{l}\text { 1.Yuan Jing } \\
\text { 2.Bahar Youssefi } \\
\text { 3.Mitra Mirhassani } \\
\text { 4.Roberto Muscedere }\end{array}$ & $\begin{array}{l}\text { An Efficient FPGA } \\
\text { Implementation of Optical } \\
\text { Character Recognition for } \\
\text { License Plate Recognition[1] }\end{array}$ & 2017 & $\begin{array}{l}\text { - The OCR is the core of an LPR system. In this work, an } \\
\text { hardware based OCR system has been implemented. } \\
\text { Advantage: A robust FPGA based OCR system has been } \\
\text { designed and tested with imperfect and noisy license plate } \\
\text { images. It was able to maintain a } 98: 2 \% \text { accuracy in } \\
\text { recognizing the characters despite the image } \\
\text { imperfections. } \\
\text { Disadvantage: It requires a proper system with selection } \\
\text { of network size, and the optimized and efficient setup of } \\
\text { the neuron activation function. }\end{array}$ \\
\hline $\begin{array}{l}\text { 1.Muayad Ali Hamood } \\
\text { Bakhtan } \\
\text { 2.Dr. Munaisyah Abdullah } \\
\text { 3. Dr. Aedah Abd Rahman }\end{array}$ & $\begin{array}{lr}\text { A Review on } & \text { License Plate } \\
\text { Recognition } & \text { System } \\
\text { Algorithms[3] } & \end{array}$ & 2016 & $\begin{array}{l}\text { - Image enhancement (preprocessing) } \\
\text { number plate extraction } \\
\text { This is a review paper hence no advantages and } \\
\text { disadvantages are listed. }\end{array}$ \\
\hline $\begin{array}{l}\text { 1. Mahesh Babu K } \\
\text { 2. M V Raghunadh }\end{array}$ & $\begin{array}{lrr}\text { Vehicle } & \text { Number } & \text { Plate } \\
\text { Detection and Recognition } \\
\text { using Bounding } & \text { Box } \\
\text { Method[4] } & & \end{array}$ & 2016 & $\begin{array}{l}\text { - The proposed system will select the image, remove noise } \\
\text { and find the interested area of image, then the license plate } \\
\text { location is extracted using edge detection then } \\
\text { segmentation of each characters individually. } \\
\text { Advantages - After noise removal, character } \\
\text { segmentation and recognition the algorithm gives an } \\
\text { accuracy of around } 91.11 \% \text {. } \\
\text { Disadvantages - Blur Images, Broken Number Plate, } \\
\text { Similarities between some characters such as O and D; } 5 \\
\text { and S; } 8 \text { and B, E; O and } 0 \text { etc. }\end{array}$ \\
\hline $\begin{array}{l}\text { 1. Y. Y. Nguwi } \\
\text { 2. W. J. Lim }\end{array}$ & $\begin{array}{l}\text { Number Plate Recognition in } \\
\text { Noisy Image[7] }\end{array}$ & 2015 & $\begin{array}{l}\text { - The system is able to tolerate noise level up to } 20 \% \text { with } \\
\text { recognition rate of } 85 \% \text {. } \\
\text { Advantage: This system is able to tolerate noise level up } \\
\text { to } 20 \% \text { with recognition rate of } 85 \% \text {. It utilizes a } \\
\text { combination of filters and morphological transformation } \\
\text { for segmenting the number plate. } \\
\text { Disadvantage: It caters only to same font and size } \\
\text { number plates }\end{array}$ \\
\hline
\end{tabular}




\begin{tabular}{|c|c|c|c|}
\hline $\begin{array}{l}\text { 1. Riazul Islam } \\
\text { 2. Kazi Fatima Sharif } \\
\text { 3. Satyen Biswas }\end{array}$ & $\begin{array}{l}\text { Automatic Vehicle Number } \\
\text { Plate Recognition Using } \\
\text { Structured Elements[8] }\end{array}$ & 2015 & $\begin{array}{l}\text { - An efficient and first computing technique for identifying } \\
\text { vehicle number plate. } \\
\text { Limited amount of computations are employed. } \\
\text { Advantage: Efficient and first computing technique for } \\
\text { identifying vehicle number plate. Computationally very } \\
\text { inexpensive as compared with most of the conventional } \\
\text { methods. } \\
\text { Disadvantage: Limited area coverage. }\end{array}$ \\
\hline $\begin{array}{l}\text { 1. Amirgaliyev Beibut } \\
\text { 2. Kairanbay Magzhan } \\
\text { 3. Kenshimov Chingiz }\end{array}$ & $\begin{array}{l}\text { Effective Algorithms and } \\
\text { Methods for Automatic } \\
\text { Number Plate Recognition[9] }\end{array}$ & 2014 & $\begin{array}{l}\text { - The paper reviews other methods and propose our } \\
\text { own algorithm. } \\
\text { The distance from camera to the vehicle will be } \\
\text { constant the performance of the proposed system will } \\
\text { increase. } \\
\text { Advantage - The car number plate pictures were } \\
\text { taken from different sides and in different climate } \\
\text { conditions and the accuracy of proposed algorithm is } \\
90 \% \text {. } \\
\text { Disadvantage - The distance from camera to the } \\
\text { vehicle and the weather conditions decreases the } \\
\text { performance of the system. Segmentation part as well } \\
\text { as optical character recognition can be improved using } \\
\text { other popular algorithms like Artificial Neural } \\
\text { Network }\end{array}$ \\
\hline $\begin{array}{l}\text { 1. Farid Bounini } \\
\text { 2. Denis Gingras } \\
\text { 3. Vincent Lapointe } \\
\text { 4. Herve Pollart }\end{array}$ & $\begin{array}{l}\text { Autonomous } \\
\text { Real Time Road Lanes } \\
\text { Detection And Tracking[10] }\end{array}$ & 2015 & $\begin{array}{l}\text { - Work deals with a road boundaries and painted lines } \\
\text { detection for intelligent and autonomous vehicles. } \\
\text { Robust against exogenous perturbations and different } \\
\text { constraints. } \\
\text { Advantage - Robust against exogenous perturbations } \\
\text { and different constraints, but good enough to control } \\
\text { the vehicle with a simple couple of fuzzy logic laws. } \\
\text { Disadvantage - The fuzzy controller handles the } \\
\text { vehicle's steering, which has a limitation for a } \\
\text { maximum speed of } 70 \mathrm{~km} / \mathrm{h} \text { in sharp turns. }\end{array}$ \\
\hline $\begin{array}{l}\text { 1. I. Sina } \\
\text { 2. A. Wibisono } \\
\text { 3. A. Nurhadiyatna } \\
\text { 4. B. Hardjono } \\
\text { 5. W. Jatmiko }\end{array}$ & $\begin{array}{l}\text { Vehicle Counting and Speed } \\
\text { Measurement Using Headlight } \\
\text { Detection.[12] }\end{array}$ & 2013 & $\begin{array}{l}\text { - We can use a few methods to detect and estimate } \\
\text { vehicle speed at night by using CCTV Camera. } \\
\text { Normalized cross-correlation has given us better } \\
\text { detection accuracy. } \\
\text { Advantages: Better detection accuracy than the } \\
\text { area-centroid-difference method. Pin-hole model has } \\
\text { given us a better accuracy. } \\
\text { Disadvantages: The miscalculation of the vehicle } \\
\text { counting happens because of the high density of the } \\
\text { road. }\end{array}$ \\
\hline
\end{tabular}




\subsection{Architecture}

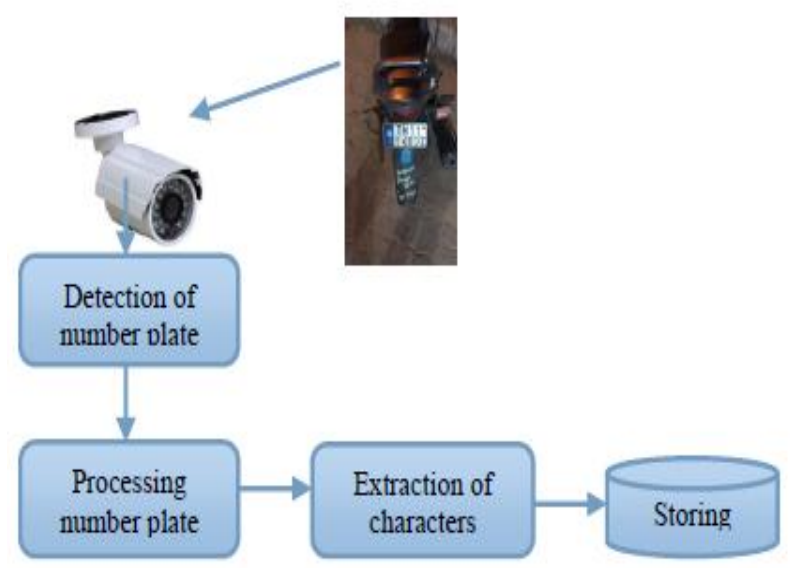

Fig 2. System Architecture

\subsection{Methodology}

Step1. Image acquisition- captures the image through HD camera and gives input to process.

Step2. Converting into color image to gray scale Image .

Step 3. Image enhancement- noise is removed using Median filter.

Step 4. Plate extraction- find columns and rows, values of the image to identify the region. Sobel edge detector is used to find the margins, then enlarged and removed connected objects. Finally, we mined the wanted region [4].

Step 5. Character segmentation- bounding box method is used to map each character, for each letter it will be planned a box and displayed each character into a single image.

Step 6. Character recognition- once segmenting each character, they are compared with the template. If each character matches, pixel-by-pixel corresponding image is found, it will be displayed into text, which as in figure the stored number plate is taken from the database, and then we apply super resolution technique to the number plate image [4]. We apply optical character recognition technique is used for backtracking of characters and then text from the number plate; we use super resolution technique to find the high accuracy image content. If the content cannot be identified clearly by the ocr it has to go through super resolution till the content is recognized by ocr. And the text is stored in the database [11].

\subsection{Display of Vehicles}

The ocr text database has stored vehicle number plate details is compared with the RTO database if the search is found then it display the details of the owner of the vehicle [11].

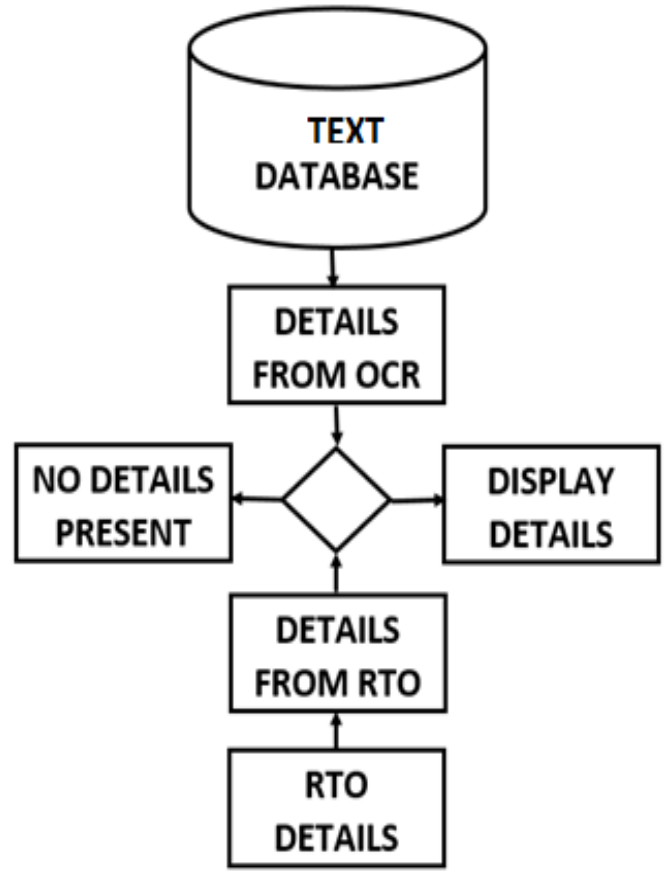

Fig 3. Display of data

\section{CONCLUSION}

Thus the survey of various Automated Number Plate Recognition System has been done and their respective flaws and advantages has been found out. The objective of this paper was to study algorithmic and calculated aspects of the automatic number plate recognition systems, such as disturbance of machine vision, pattern recognition, OCR. There is a strong series of algorithms applied during the recognition process. Hence the future aspects of ANPR should concentrate on High Definition plate, Fancy Plates \& multi plates processing at a time.

\section{REFERENCES}

[1] Yuan Jing, Bahar Youssefi, Mitra Mirhassani, Roberto Muscedere "An Efficient FPGA Implementation of Optical Character Recognition for License Plate Recognition" University of Windsor, ON, Canada,2017 IEEE

[2] Worawut Yimyam, Mahasak Ketcham "The Automated Parking Fee Calculation Using License Plate Recognition System" Universitas Gadjah Mada Yogyakarta, Indonesia, 2017 IEEE.

[3] Muayad Ali Hamood Bakhtan, Dr. Munaisyah Abdullah, Dr. Aedah Abd Rahman "A Review on License Plate Recognition System Algorithms”, IEEE 2016.

[4] Mahesh Babu K, M V Raghunadh." Vehicle Number Plate Detection and Recognition using Bounding Box Method", 2016 IEEE.

[5] Zhiyi Li, Mohammad Shahidehpour, Shay Bahramirad, Amin Khodaei, "Optimizing Traffic Signal Settings in Smart Cities", IEEE 2015.

[6] J. Albert Mayan, Kumar Akash Deep, Livingston Alvin, Siva Prasad Reddy "Number Plate Recognition using Template Comparison for various fonts in MATLAB", IEEE 2016. 
[7] Y. Y. Nguwi W. J. Lim," Number Plate Recognition in Noisy Image",2015.

[8] Riazul Islam, Kazi Fatima Sharif, Satyen Biswas, "Automatic Vehicle Number Plate Recognition Using Structured Elements", IEEE 2014.

[9] Amirgaliyev Beibut,Kairanbay Magzhan,Kenshimov Chingiz," Effective Algorithms and Methods for Automatic Number Plate Recognition”,2014 IEEE

[10] Farid Bounini,Denis Gingras,Vincent Lapointe,Herve Pollart," Autonomous Vehicle And Real Time Road
Lanes Detection And Tracking", Proceedings of 2015 IEEE

[11] Balamurugan G., Sakthivel Punniakodi, Rajeswari K. and Arulalan V. "Automatic number plate recognition system using super-resolution technique", 2015 International Conference on Computing and Communications Technologies (ICCCT), 2015.

[12] Sina,A. Wibisono,A. Nurhadiyatna,B. Hardjono,W. Jatmiko," Vehicle Counting and Speed Measurement Using Headlight Detection.", Proceedings of the 2013 IEEE. 